\title{
Journal of Applied Research and Technology
}

\author{
Original
}

\section{Chaos embedded particle swarm optimization algorithm-based solar optimal Reflex ${ }^{\mathrm{TM}}$ frequency charge}

\author{
Jui-Ho Chen, Her-Terng Yau*, Jin-Han Lu \\ Department of Electrical Engineering, National Chin-Yi University of Technology, Taichung, Taiwan
}

Received 19 April 2014; accepted 18 August 2014

\begin{abstract}
The battery temperature rise and charge efficiency during the long-term charge in the sun are a very important topic. The traditional common constant current and constant voltage result in quick temperature rise and influence the charge efficiency indirectly. Therefore, the Reflex ${ }^{\mathrm{TM}}$ charge is adopted, the chemical reaction of electrolyte is buffered during discharge, so that the battery temperature rises slightly during charge. However, there is no optimum frequency for switching loss and charge efficiency during Reflex ${ }^{\mathrm{TM}}$ charge. Therefore, this paper proposes using chaos embedded particle swarm optimization algorithm (CPOS) to minimize the switching loss of battery in charge and discharge conditions. The battery module in Matlab/Simulink environment is used for solar charge, multiple charge modes are compared with traditional common methods. The simulation results show that the Reflex ${ }^{\mathrm{TM}}$ method has improved the battery temperature in Matlab/Simulink, and the State of Charge (SOC) is equivalent to other charge modes. It is proved that the method proposed in this paper has significant effect on switching loss and oscillation, and its charge efficiency is equivalent to traditional quick charge.

All Rights Reserved (C) 2015 Universidad Nacional Autónoma de México, Centro de Ciencias Aplicadas y Desarrollo Tecnológico. This is an open access item distributed under the Creative Commons CC License BY-NC-ND 4.0.
\end{abstract}

Keywords: CPSO; Reflex ${ }^{\mathrm{TM}}$; Charge; SOC

\section{Introduction}

At present, the demand for energy increases day after day, and most of energy is derived from nuclear energy. The Japan's nuclear event in recent years exaggerated the nuclear safety issue to the people, so the renewable energy is paid closer attention to. Among numerous green energy sources, the solar power is the most convenient energy at lowest cost, because it is free from topographic effect and environmental pollution. It is extensively used in domestic solar water heaters, solar powered vehicles and so on. Therefore, efficient solar charge becomes an important point.

The traditional solar power generation module is always connected to a set of buck, boost or buck-boost converter, which stabilizes, boosts and reduces the voltage of the electricity generated by the photovoltaic panel, to supply the electricity to primary system or to store the energy. The solar power generation uses converter for Maximum Power Point Tracker (MPPT); the maximum power point is obtained from the voltage-power characteristic curve, according to which the photovoltaic panel output efficiency is maximized.

\footnotetext{
*Corresponding author.

E-mail addresses: pan1012@ms52.hinet.net; htyau@ncut.edu.tw (H.Y. Yau).
}

The common algorithms for MPPT include the variable step incremental conductance proposed by Fangrui Liu in 2008 (Liu et al., 2008; Mei et al., 2011) and Perturb and Observe (P\&O) proposed by Nicola Femia in 2005 (Femia et al., 2005) and so on. In terms of charge, the common charge-up methods of photovoltaic panel power generation system include constant current (CC) charge-up method, constant voltage (CV) charge-up method, constant current-constant voltage (CC-CV) charge-up method, pulse charge-up method, Reflex ${ }^{\mathrm{TM}}$ charge-up method and so on (Lemaire-Potteau et al., 2009).

In terms of the present studies of battery charging, LiangRui Chen proposed the variable frequency pulse charge system (VFPCS) in 2007 which could detect optimum charging frequency (Chen, 2007), and compared multiple charge modes with fixed frequency, the charge efficiency was increased to a great extent compared with traditional $\mathrm{CV}$ and $\mathrm{CC}$, but the defect was that there was no specific definition to prove the frequency obtained by the algorithm was the optimal solution. In 2009, Li Siguang proposed the multistage constant currentconstant voltage (MCC-CV) (Li, Zhang \& Xie, 2009), the experimental data showed the temperature rise was improved effectively and the charge efficiency was influenced indirectly. Hsieh et al. (2012) proposed the comparison between PV-PC and $\mathrm{CC}-\mathrm{CV}$ charge efficiencies in different maximum power 
point tracking (MPPT) conditions. The results showed the capacity and voltage charge efficiency were better, and the pulse charge-up method contributed to the chemical reaction of battery and prolonged the battery life.

In terms of the studies of solar battery charging related algorithms, Liu et al. (2005) proposed Ant-Colony-System (ACS), which was used to look for the most efficient charge-up method. The optimal solution was obtained within a short time based on the random search method of ACS, multichannel battery test advantage and clonal genetic algorithm. Yau et al. (2012) proposed the extremum search of Genetic algorithms (GA) in PI controller, and used IAE convergence property to obtain the optimum extremum value. Finally, the characteristics of controller were used to suppress high frequency noise and eliminate the steady-state error of system for stable CV charge.

This paper uses lead-acid battery as the energy storage tank, because the lead-acid battery has the longest history of application, as well as the most mature battery. It is characterized by low price, mass production and extensive application. The charge mode is Reflex ${ }^{\mathrm{TM}}$ as literature (Wang et al., 2007), the $12 \mathrm{~V} / 7$ Ah lead-acid battery is used for 3C charging experiment, and the Reflex ${ }^{\mathrm{TM}}$ charge-up method is used to control the temperature at a level successfully. The results show that the Reflex ${ }^{\mathrm{TM}}$ charge contributes the chemical reaction inside the lead-acid battery, i.e. buffering the temperature rise. Therefore, this paper proposes using CV-Reflex ${ }^{\mathrm{TM}}$ quick charge and CPSO (Eberhart \& Kennedy, 1995; Wang \& Meng, 2007) for Reflex ${ }^{\mathrm{TM}}$ chaging frequency optimization search. First, the Taguchi method and orthogonal array $L_{16}\left(4^{3}\right)$ are used for multiple calculations to find out the optimal values of $C_{1}, C_{2}$ and $W$ parameters. The logistic map (Lloyd, 1995) (uniform random value when $r=4$ ) and the position function of particle swarm optimization (Laguna-Sánchez et al., 2009; Jamali et al., 2013) 2013) are used to increase the parameter update rate. Finally, the optimal solution is found based on the integral square error (ISE) energy consumption criteria.

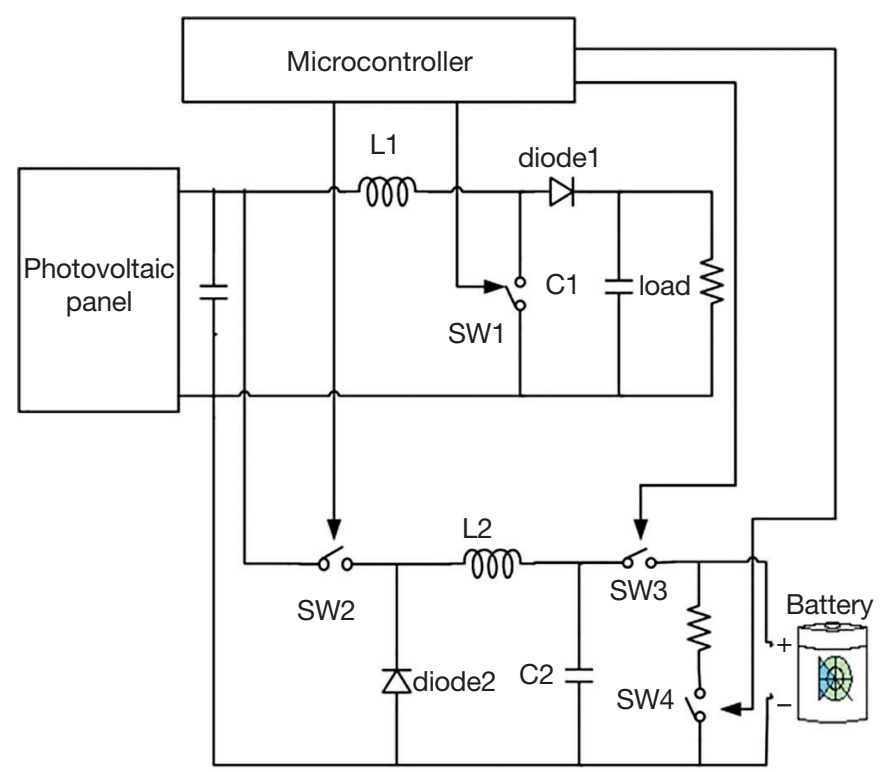

Fig. 1. System circuit diagram.
Section 2 shows the solar power system structure of this paper, and briefly introduces the converter operation. Section 3 introduces the CPSO and the optimum parameter design obtained by Taguchi orthogonal array. Section 4 compares and discusses the simulation results and traditional common charge-up methods. Section 5 shows the conclusions.

\section{Architecture of solar power system}

In this paper, the solar energy is supplied by booster to the master system for signal acquisition and monitoring. In terms of storage tank, the buck converter stores the residual energy in the lead-acid battery, and the microcontroller calculates and exports pulse width modulation (PWM) to control switching. Figure 1 is the system circuit diagram of overall architecture. Table 1 shows the simulated photovoltaic panel specifications.

\subsection{On-off switching modes}

In literature (Chao et al., 2013), the charge mode is switched after a period of time due to excessive temperature or better charge efficiency, e.g. battery temperature reduction by low charging current or rest. Therefore, the charge mode is switched at intervals of one hour in this paper. In solar power generation, the back end buck converter implements $\mathrm{CV}$ charge for the emergency power supply, the switches 2 and 3 are on, the switch 4 is off; see Mode 1 in the Figure 2.

When the solar power generation lasts a certain time or reaches a temperature, the $\mathrm{CV}$ is changed to Reflex ${ }^{\mathrm{TM}}$ chargeup method, the switches 2 and 4 are on, and the switch 3 is off for short-term low current discharge of the resistor; see Mode 2 in the Figure 3.

\subsection{Influence of Reflex ${ }^{T M}$ on battery temperature rise}

The reduction of chemical reaction of the positive electrode plate of lead-acid oxidation reaction occurs at the electrode

Table 1

KC65T photovoltaic panel specifications $\left(1000 \mathrm{~W} / \mathrm{m}^{2}\right.$, AM $\left.1.5,25^{\circ} \mathrm{C}\right)$.

\begin{tabular}{ccccc}
\hline$P_{\max }$ & $V_{M M P}$ & $I_{M M P}$ & $\mathrm{~V}_{o c}$ & $I_{s c}$ \\
\hline $65 \mathrm{~W}$ & $17.4 \mathrm{~V}$ & $3.75 \mathrm{~A}$ & $21.7 \mathrm{~V}$ & $3.99 \mathrm{~A}$ \\
\hline
\end{tabular}

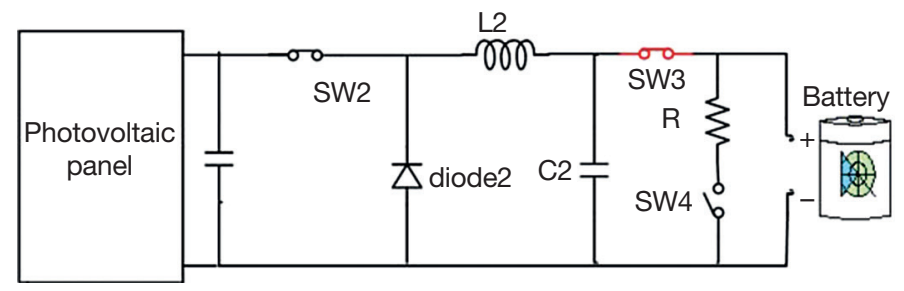

Fig. 2. Mode 1. 
plate of a lead storage battery and the cathode plate to produce lead sulfate (Pavlov et al., 2005). The chemical equation of battery is expressed as equation (1).

$$
\mathrm{PbO}_{2(\mathrm{~s})}+2 \mathrm{H}_{2} \mathrm{SO}_{4(\mathrm{aq})}+\mathrm{Pb}_{(\mathrm{aq})} \rightleftarrows 2 \mathrm{PbSO}_{4(\mathrm{~s})}+2 \mathrm{H}_{2} \mathrm{O}_{(1)}
$$

The traditional rapid charging lasts long, so the electrolyte does not have relaxation time, causing temperature rise and shortening the cycle life of battery. As shown in Figure 4, the characteristic of Reflex ${ }^{\mathrm{TM}}$ is that each positive pulse $t_{l}$ charge is followed by a short negative pulse $t_{2}$ discharge, so that the chemical reaction in the electrolyte has relaxation time, and the battery overcharging is prevented. The temperature rise can be improved effectively, and the battery cycle life can be prolonged.

\section{Chaos embedded particle swarm optimization algorithm (CPSO) and parameter optimization design}

This paper uses Matlab R2012a to design the photovoltaic panel charging architecture, the lead-acid battery in Matlab/ Simulink is used to compare the charge efficiency and temperature in different charge modes. Figure 5 shows the photovoltaic panel supplies electricity to the master system and charges the battery, the voltage and current data of series resistor and battery are fed back and the charge-up method is selected and calculated in the micro control system.

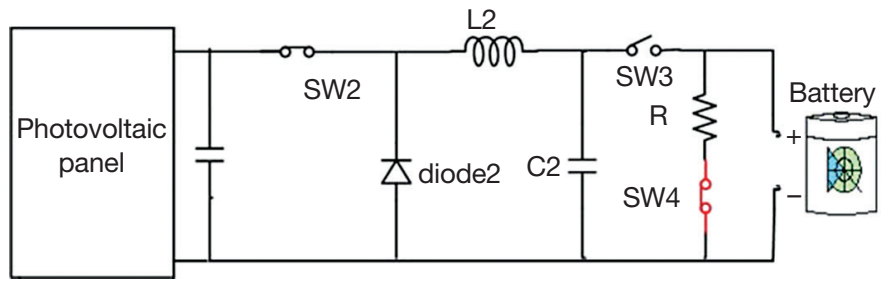

Fig. 3. Mode 2.

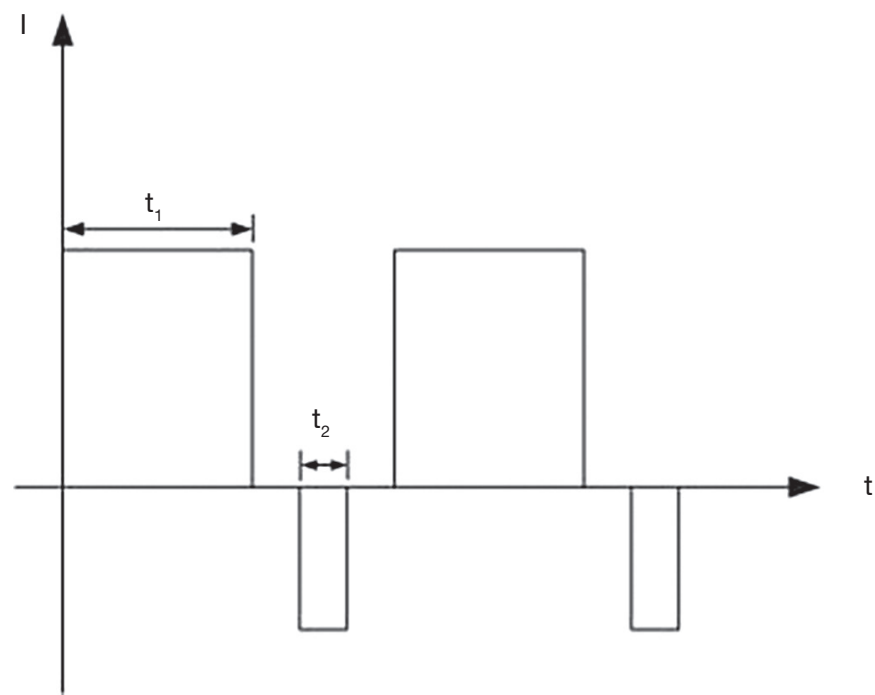

Fig. 4. Charging and discharging intervals of Reflex ${ }^{\mathrm{TM}}$.

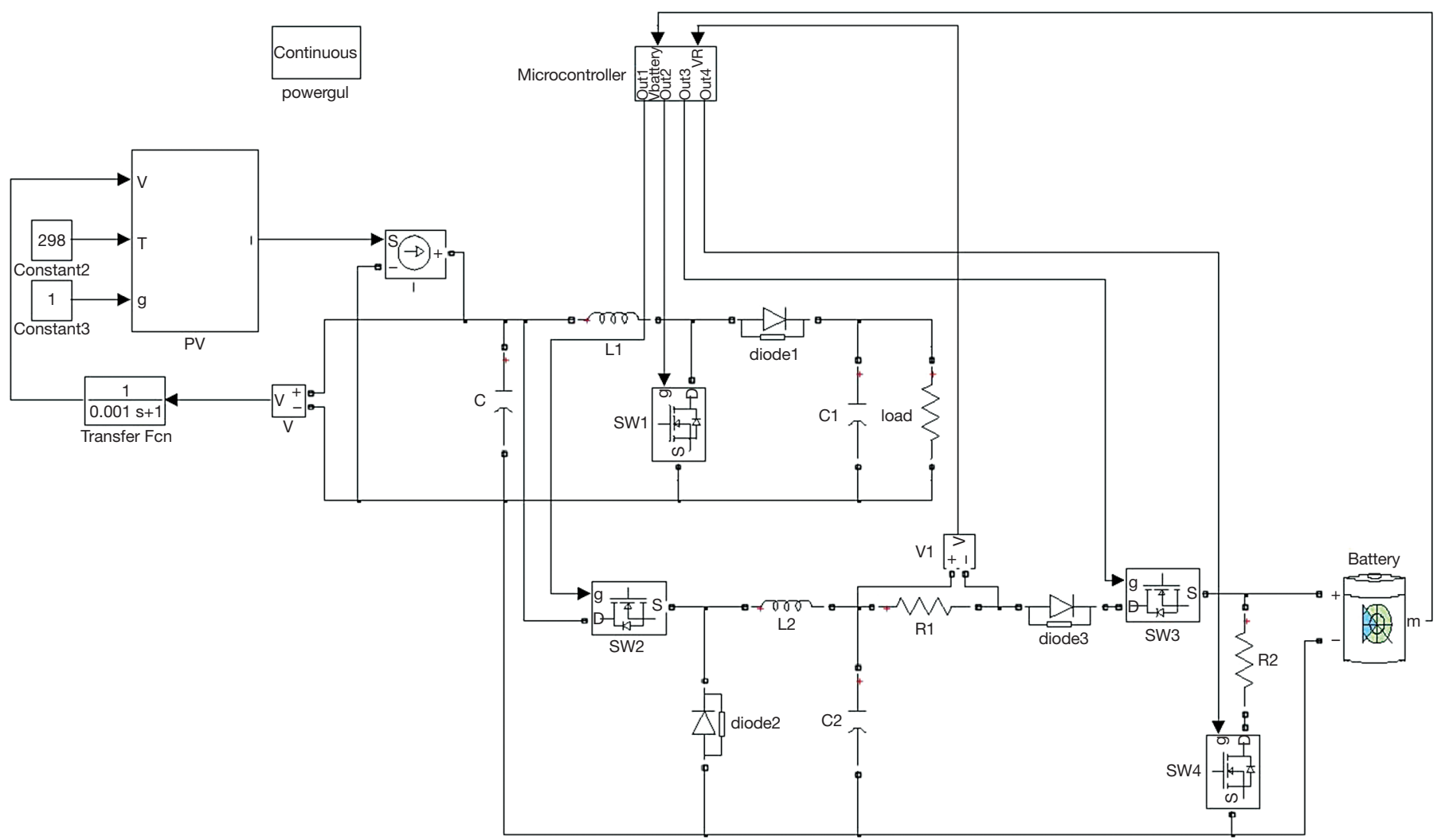

Fig. 5. Matlab/simulink solar power system architecture. 


\section{1. $C P S O$}

A good solar charge mode shall improve the battery charging efficiency, for example, the common problem is excess temperature caused bad charge efficiency, the charge frequency influences the battery charge-discharge switching loss, influencing the battery temperature rise and the charge efficiency and solar energy output stability. Therefore, this paper proposes using CPSO to look for the frequency minimizing the battery charging and discharging loss. The optimal solution is found by five times the experiment thirty times iterations of PSO (Park et al., 2005). Equations (2) and (3) are the basic algorithm of PSO. Figure 6 is the PSO flow chart (Garcia-Nieto et al., 2013).

$$
\begin{gathered}
V_{n}(t)=W \times V_{n}(t-1)+C_{1} \times \text { Rand } \times \\
\left(\text { pbest }-X_{n}\right)+C_{2} \times \text { Rand } \times\left(\text { gbest }-X_{n}\right) \\
X_{n}(t)=X_{n}(t-1)+V_{n}(t)
\end{gathered}
$$

where $V_{n}$ is particle update rate; $n$ is particle code; $W$ is inertia weight; $C_{1}, C_{2}$ are learning constants; Rand is randomly generated $0 \sim 1$ random number; pbest is optimal solution of current particle; gbest is optimal solution up to current particle, and $X_{n}$ is current position of particle.

The major factors influencing the optimal solution include position function and update rate. The logistic map generates 0 to 1 uniform random number randomly when $r=4$, as shown in Figure 7. The logistic map disorder is calculated by entropy

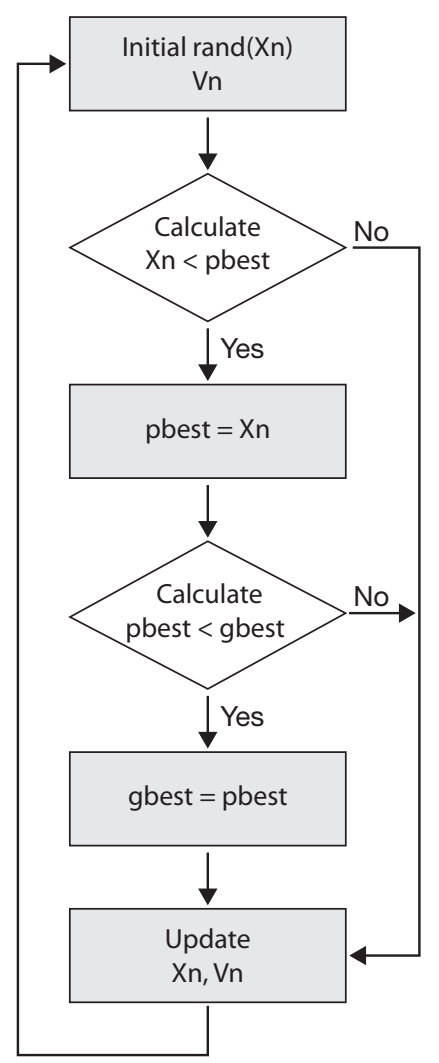

Fig. 6. Particle swarm optimization (PSO) flow chart.
(Clack, 2008); as shown in Figure 8, it is observed that the disorder is at its maximum when $r=4$, the original Rand function is replaced by logistic map — equation (4) — based on the characteristic of uniform random number.

$$
a_{n+1}=r \cdot a_{n}\left(1-a_{n}\right)
$$

The ISE criteria, equation (5), represent the energy consumption, based on which the system performance is evaluated. This paper designs $(t)$ as the optimum switching loss and the switching consumption error at different frequencies, $t$ is the time. The optimum frequency is obtained from multiple better frequencies in CPSO and ISE criteria, as shown in Figures 9 and 10. The following figures show the frequency curve converges at $90 \mathrm{~Hz}$, the ISE curve converges at 0.2 .

$$
I S E=\int_{0}^{\infty}[e(t)]^{2} d t
$$

\subsection{PSO parameter optimization design}

The Taguchi orthogonal array is applied to the parameter design in PSO, the original 64 tests are reduced to 16 tests by the

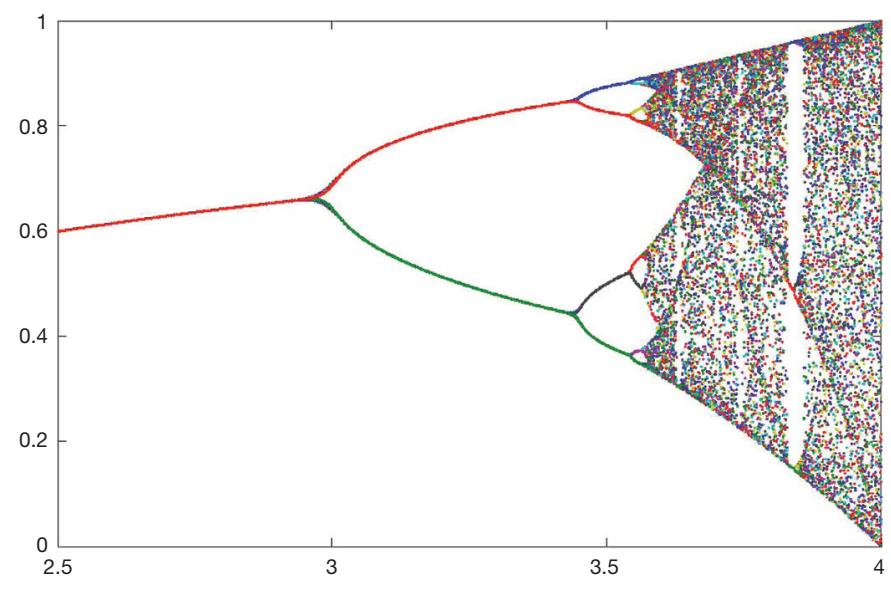

Fig. 7. Logistic map.

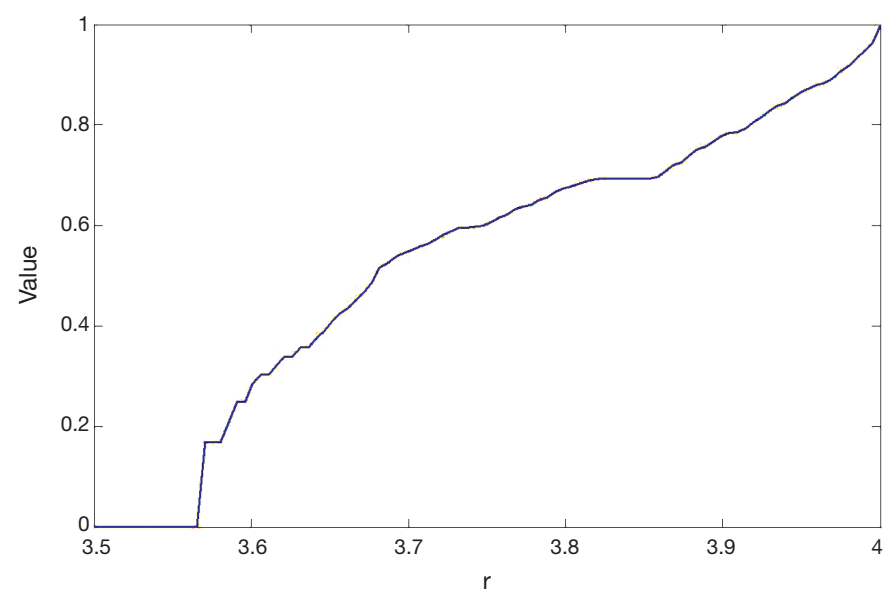

Fig. 8. Entropy of logistic map. 


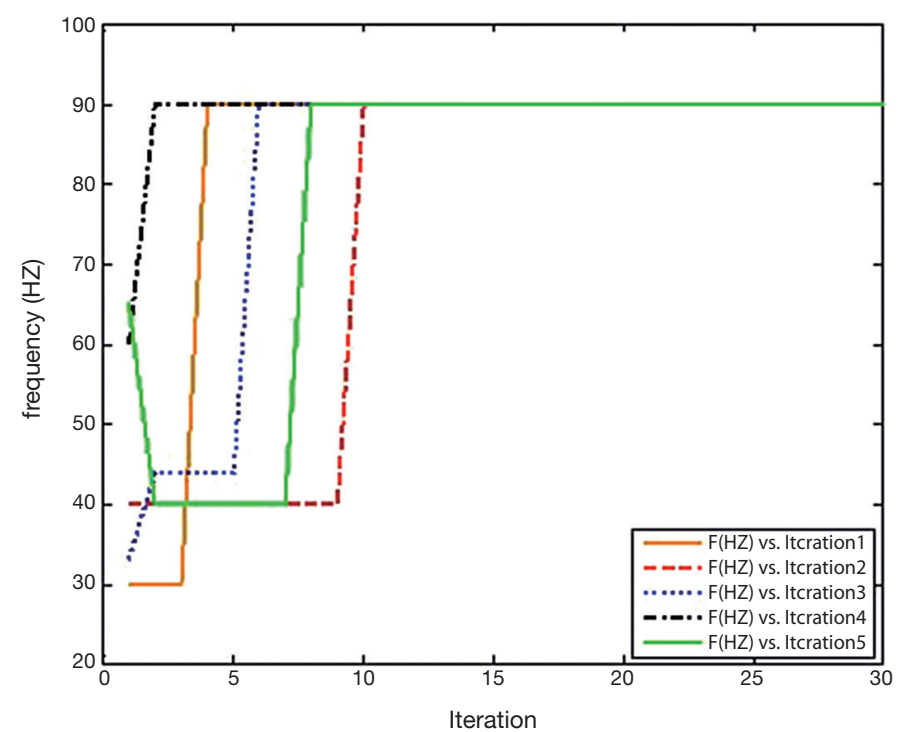

Fig. 9. Frequency convergence curve of chaos embedded particle swarm optimization algorithm (CPSO).

characteristics of Taguchi orthogonal array, so as to obtain the optimal values of parameters. The optimal parameters are selected in orthogonal array, as shown in Table 2, the values with minimum sum of parameters are shown in Table 3 , representing the parameters with fewer iterations and updated fastest, $C_{1}, C_{2}$ and $W$ are 1,1 and 0.75 respectively.

\section{Charging system simulation results and discussion}

In the charging simulation results, the charge-up methods in Figure 11 include CC-CV, CV-pulse and CV-Reflex ${ }^{\mathrm{TM}}$; the

Table 2

$L_{16}\left(4^{3}\right)$ orthogonal array.

\begin{tabular}{cllll}
\hline No. & $C_{I}$ & \multicolumn{1}{c}{$\mathrm{C}$} & $\mathrm{W}$ & \multicolumn{1}{c}{ ISE } \\
\hline 1 & 0.5 & 0.5 & 0.25 & 15.9916 \\
2 & 0.5 & 1 & 0.5 & 14.3003 \\
3 & 0.5 & 1.5 & 0.75 & 12.9263 \\
4 & 0.5 & 2 & 1 & 15.2632 \\
5 & 1 & 0.5 & 0.5 & 13.2109 \\
6 & 1 & 1 & 0.75 & 14.2958 \\
7 & 1 & 1.5 & 1 & 15.2053 \\
8 & 1 & 2 & 0.25 & 13.4398 \\
9 & 1.5 & 0.5 & 0.75 & 14.8840 \\
10 & 1.5 & 1 & 1 & 13.7801 \\
11 & 1.5 & 1.5 & 0.25 & 15.8506 \\
12 & 1.5 & 2 & 0.5 & 16.0153 \\
13 & 2 & 0.5 & 1 & 14.9186 \\
14 & 2 & 1 & 0.25 & 13.7045 \\
15 & 2 & 1.5 & 0.5 & 14.0647 \\
16 & 2 & 2 & 0.75 & 13.9744 \\
\hline
\end{tabular}

Table 3

Optimal parameter calculation.

\begin{tabular}{llll}
\hline & \multicolumn{1}{c}{$\mathrm{C}_{1}$} & \multicolumn{1}{c}{$\mathrm{C}_{2}$} & $\mathrm{~W}$ \\
\hline$L_{1}$ & 58.4814 & 59.0051 & 58.9865 \\
$L_{2}$ & 56.1518 & 56.0807 & 57.5912 \\
$L_{3}$ & 60.53 & 58.0469 & 56.0805 \\
$L_{4}$ & 56.6622 & 58.6927 & 59.1672 \\
\hline
\end{tabular}

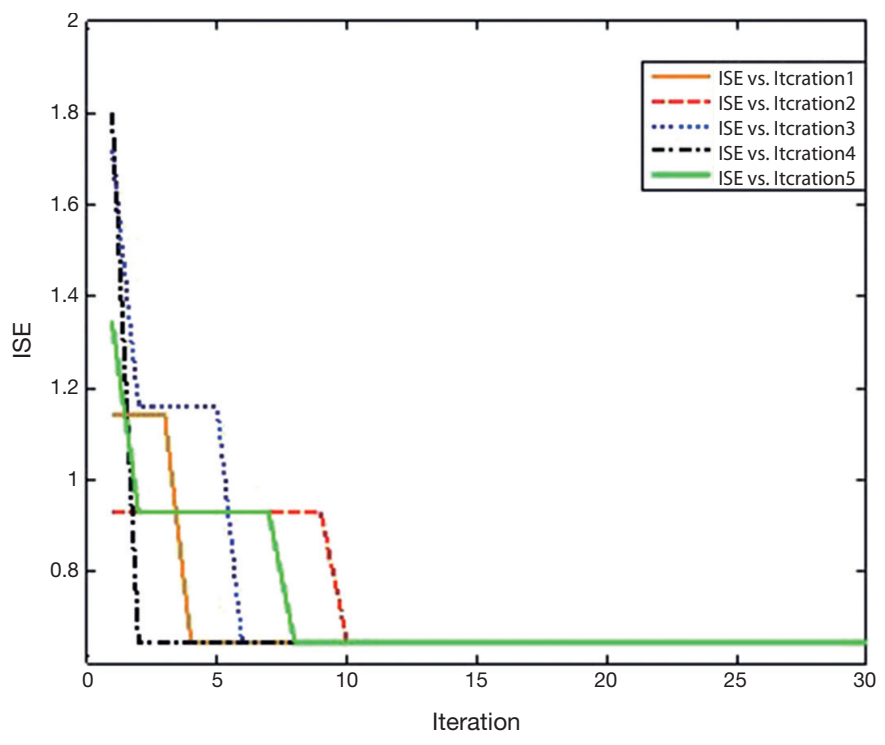

Fig. 10. Integral square error (ISE) convergence curve of chaos embedded particle swarm optimization algorithm (CPSO).

current waveform in partial period is magnified, as shown in Figure 12. It is observed that the pulse charge-up method has larger switching loss and larger oscillation than Reflex ${ }^{\mathrm{TM}}$ during battery charge-discharge switching, causing temperature rise and reducing the charge efficiency. Figure 13 shows the $\mathrm{CC}-\mathrm{CV}$ charge is fastest. Figure 14 also magnifies partial time. Figure 15 shows the battery SOC of different charge-up methods. It is observed that the CC-CV is the fastest charge-up method, but in terms of temperature, it is most likely to lose battery life. According to the battery temperature in Figure 16 and literatures (Watrin et al., 2011; Awwad et al., 2012; Yamamoto et al., 2013; Boico et al., 2007; Huang et al., 2009), the pulse and Reflex ${ }^{\mathrm{TM}}$ can suppress temperature, but the pulse has larger chargedischarge switching loss and oscillation as mentioned above. Therefore, the charge of CPSO with Reflex ${ }^{\mathrm{TM}}$ charge proposed in this paper can suppress the battery temperature, the charge rate is equivalent to the $\mathrm{CC}-\mathrm{CV}$ quick charge.

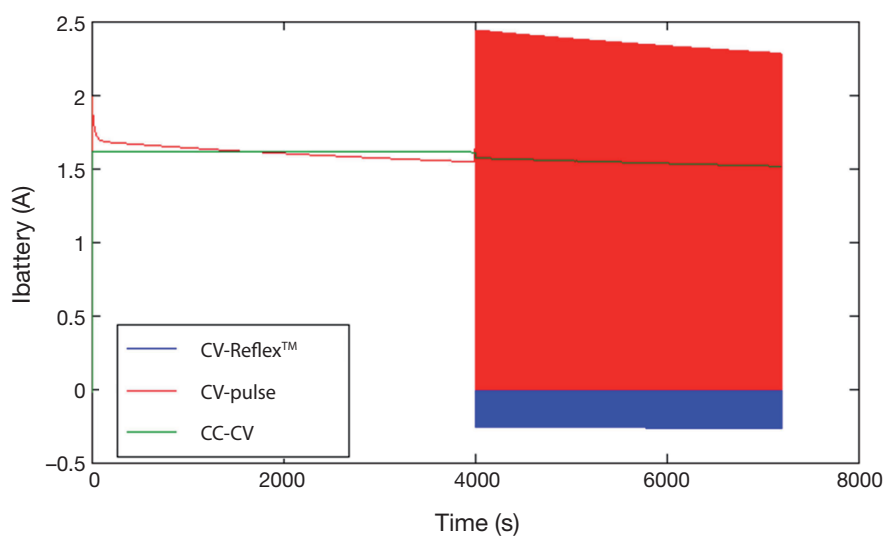

Fig. 11. Battery current comparison diagram. 


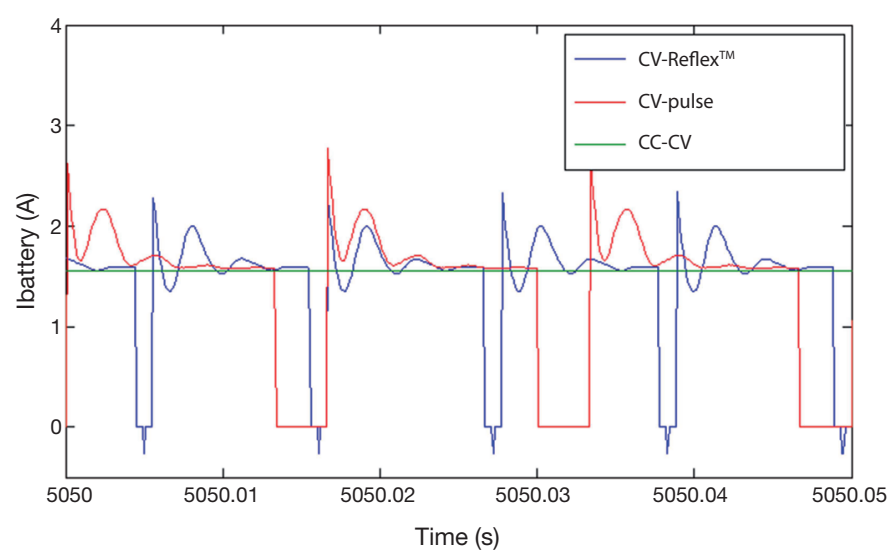

Fig. 12. Battery current enlarged view.

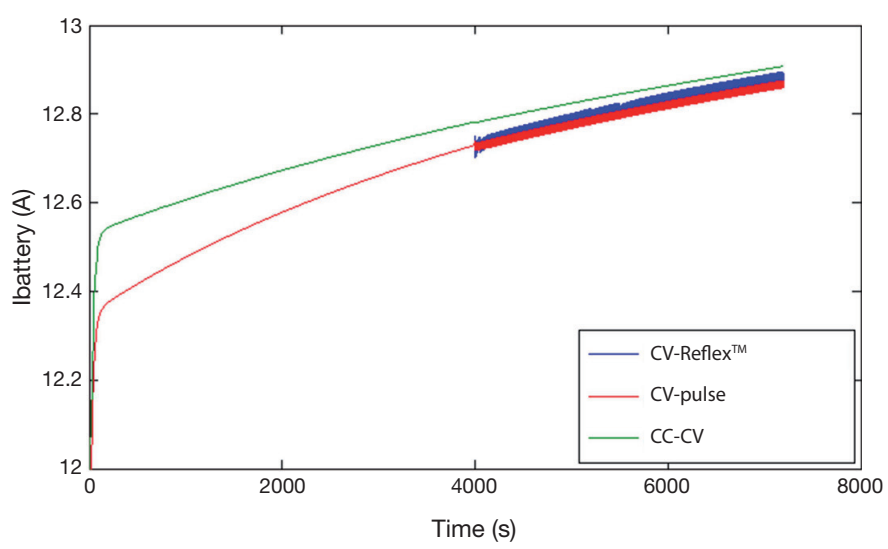

Fig. 13. Battery voltage comparison diagram.

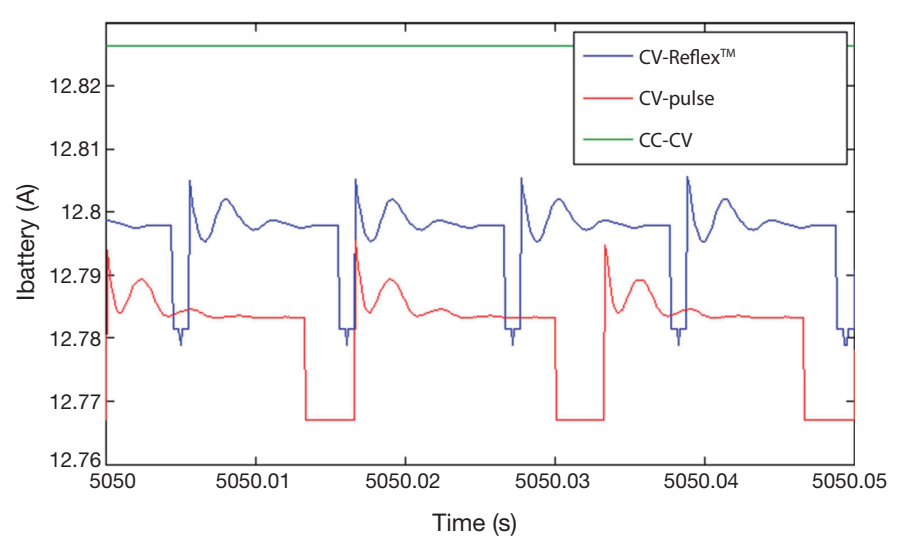

Fig. 14. Battery voltage enlarged view.

\section{Conclusions}

The CPSO proposed in this paper is used to estimate the frequency of Reflex ${ }^{\mathrm{TM}}$ charge. The CPSO convergence frequency curve obtained by simulation shows the frequency is mostly better than common Reflex ${ }^{\mathrm{TM}}$ charge, not only improving the charge-discharge switching loss and oscillation, and the Re$\mathrm{flex}^{\mathrm{TM}}$ can improve the temperature rise resulted from $\mathrm{CC}-\mathrm{CV}$,

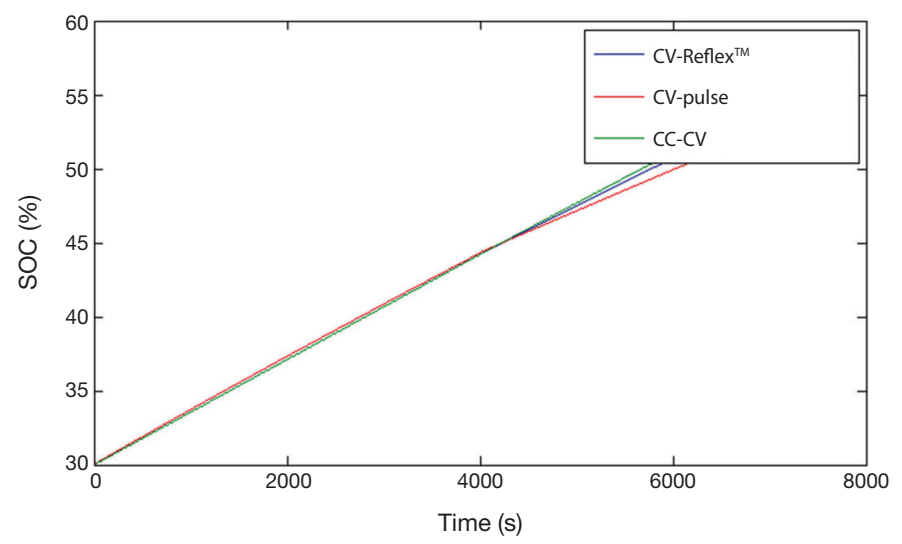

Fig. 15. Battery capacity comparison diagram.

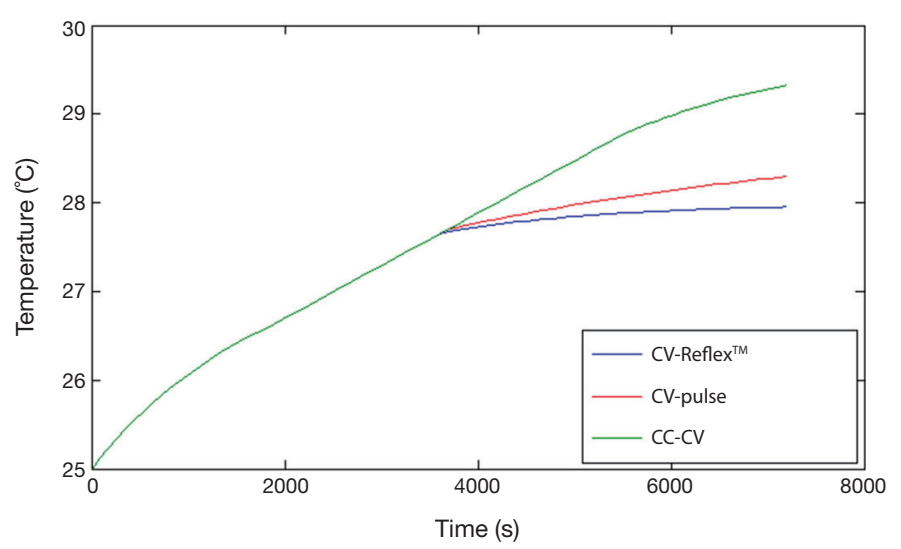

Fig. 16. Battery temperature comparison diagram.

it overcomes the excess temperature during charge, and it has high charge efficiency and it does not shorten the cycle life of battery. Therefore, it is proved that the CPSO optimized frequency proposed in this paper can remedy common problems in charge.

\section{Acknowledgements}

Financial support for this research is provided by the National Science Council of Taiwan, under the Project No. NSC100-2628-E-167 -002 -MY3 is greatly appreciated.

\section{References}

Awwad, R., Das, R., Arabi, T., \& Hajj, H. (2012). A fast charging Multi-C technique for mobile devices. 2012 International Conference on Energy Aware Computing, Guzelyurt (pp. 1-7).

Boico, F., Lehman, B., \& Shujaee, K. (2007). Solar Battery Chargers for NiMH Batteries. IEEE Trans. Power Electron., 22, 1600-1609.

Chao, P., Chen, W.D., \& Cheng, C.W. (2013). A fast battery charging algorithm for an intelligent PV system with capability of on-line temperature compensation. Microsystem Technologies, 19, 1289-1306.

Chen, L.R. (2007). A design of an optimal battery pulse charge system by frequency-varied technique. IEEE Trans. Ind. Electron, 54, 398-405. 
Clack, G. (2008). Entropy and dynamics (Dissertation). York, UK: MSc in Mathematics with Modern Applications, Department of Mathematics, University of York.

Eberhart, R., \& Kennedy, J. (1995). A new optimizer using particle swarm theory. Proceedings of the Sixth International Symposium on Micro Machine and Human Science, Nagoya (pp. 39-43).

Femia, N., Petrone, G., Spagnuolo, G., \& Vitelli, M. (2005). Optimization of perturb and observe maximum power point tracking method. IEEE Trans. Power Electron., 20, 963-973.

Garcia-Nieto, J., Olivera, A.C., \& Alba, E. (2013). Optimal cycle program of traffic lights with particle swarm optimization. IEEE Trans. Evol. Comput., 17, 823-839.

Hsieh, H.I., Shih, S.F., Hsieh, J.H., \& Hsieh, G.C. (2012). A study of highfrequency photovoltaic pulse charger for lead-acid battery guided by PIINC MPPT. International Conference on Renewable Energy Research and Applications (ICRERA), Nagasaki (pp. 1-6).

Huang, C.H., Huang, C.H., Ou, T.C., Lu, K.H., \& Hong, C.M. (2009). Intelligent fuzzy logic controller for a solar charging system. IEEE/ ASME International Conference on Advanced Intelligent Mechatronics, Singapore (pp. 1412-1417).

Jamali, S., Rezaei, L., \& Gudakahriz, S.J. (2013). An energy-efficient routing protocol for MANETs: a particle swarm optimization approach. Journal of Applied Research and Technology, 11, 803-812.

Laguna-Sánchez, G.A., Olguín-Carbajal, M., Cruz-Cortés, N., BarrónFernández, R., \& Álvarez-Cedillo, J.A. (2009). Comparative study of parallel variants for a particle swarm optimization algorithm implemented on a multithreading GPU. Journal of Applied Research and Technology, 7, 292-309.

Lemaire-Potteau, E., Perrin, M., \& Genies, S. (2009). Charging methods. Encyclopedia of Electrochemical Power Sources (pp. 413-423).

Li, S., Zhang, C., \& Xie, S. (2009). Research on fast charge method for leadacid electric vehicle batteries. International Workshop on Intelligent Systems and Applications, Wuhan (pp. 1-5).

Liu, F., Duan, S., Liu, F., Liu, B., \& Kang, Y. (2008). A variable step size INC MPPT method for PV systems. IEEE Trans. Ind. Electron., 55, 2622-2628.
Liu, Y.H., Teng, J.H., Lin, Y.C. (2005). Search for an optimal rapid charging pattern for lithium-ion batteries using ant colony system algorithm. IEEE Trans. Ind. Electron, 52, 1328-1336.

Lloyd, A.L. (1995). The coupled logistic map: a simple model for the effects of spatial heterogeneity on population dynamics. J. Theor. Biol., 173, 217230.

Mei, Q., Shan, M., Liu, L., \& Guerrero, J.M. (2011). A novel improved variable step-size a novel improved variable step-size method for PV systems. IEEE Trans. Ind. Electron, 58, 2427-2434.

Park, J.B., Lee, K.S., Shin, J.R., \& Lee, K.Y. (2005). A particle swarm optimization for economic dispatch with nonsmooth cost functions. IEEE Trans. Power Syst., 20, 34-42.

Pavlov, D., Kirchev, A., \& Monahov, B. (2005). Mechanism of the oxygen cycle reactions proceeding at the negative plates of VRLA batteries. Institute of Electrochemistry and Energy Systems, 144, 521-527.

Altinoz, O.T., Yilmaz, A.E., \& Weber, G.W. (2012). Application of chaos embedded PSO for PID parameter tuning. International Journal of Computers, Communications and Control, 7, 204-217.

Wang, S., \& Meng, B. (2007). Chaos particle swarm optimization for resource allocation problem. IEEE International Conference on Automation and Logistics, Jinan (pp. 464-467).

Wang, T.W., Yang, M.J., Shyu, K.K., \& Lai, C.M. (2007). Design fuzzy SOC estimation for sealed lead-acid batteries of electric vehicles in Reflex ${ }^{T M}$. IEEE International Symposium on Industrial Electronics, Vigo (pp. 95-99).

Watrin, N., Bouquain, D., Blunie, B., \& Miraoui, A. (2011). Multiphysical lithium-based battery pack modeling for simulation purposes. IEEE Vehicle Power and Propulsion Conference (VPPC), Chicago (pp. 1-5).

Yamamoto, Y., Kato, K., Lei, L., \& Fukui, M. (2013). A thermal management system for lithium-ion battery in mobile systems. 2013 European Conference on Circuit Theory and Design (ECCTD), Dresden (pp. 1-4).

Yau, H.T., Liang, Q.C., \& Hsieh, C.T. (2012). Maximum power point tracking and optimal Li-ion battery charging control for photovoltaic charging system. Comput. Math. Appl., 64, 822-832. 